\title{
Craniopharyngioma - a childhood and adult disease with challenging characteristics
}

\section{Hermann L. Müller*}

Department of Pediatrics, Klinikum Oldenburg gGmbH, Oldenburg, Germany

*Correspondence: mueller.hermann@klinikum-oldenburg.de

Edited by:

Shlomo Melmed, Burns and Allen Research Institute, USA

Craniopharyngiomas are rare embryogenic malformations of the sellar area with low-grade histological malignancy. Despite high survival rates ( $87-95 \%$ in recent series), quality of life is frequently impaired in long-term survivors due to sequelae caused by the anatomical proximity of the tumor to the optic nerve, pituitary gland, and hypothalamus - in many cases even entanglement with the hypothalamus (Cohen et al., 2011; Müller, 2011; Zoicas and Schöfl, 2012). One of the most serious quality of life complications of craniopharyngioma is hypothalamic obesity or so-called "hypothalamic syndrome," a problem that can manifest before and/or after treatment. Novel insights into mechanisms of neuroendocrine satiety regulation and the pathogenic relevance of the autonomous nervous system are expected to facilitate future therapeutic approaches for hypothalamic syndrome (Elfers and Roth, 2011; Lustig, 2011; Roth, 2011).

For the time being, current treatment options for craniopharyngioma patients suffering from hypothalamic syndrome are limited, the most effective to date being bariatric surgery. Bariatric surgery is tolerable and effective in weight-reduction for severely obese adult craniopharyngioma patients (Bingham et al., 2012), but considered intrusive and therefore controversial for younger patients. A substantial improvement in prognosis of craniopharyngioma will require the development of risk adapted neurosurgical (Flitsch et al., 2011; Bartels et al., 2012; Puget, 2012; Trippel and Nikkhah, 2012) and radiooncological (Kortmann, 2011) treatment strategies in a multidisciplinary approach. Recent multicenter cooperation in this area has already led to beneficial results.

The consequences of both the surgical treatment and post-surgical management of the disease are as complicated and hypothalamic-intertwined as the tumors themselves. Risk adapted surgical strategies at initial diagnosis should aim at a maximal degree of resection, respecting the integrity of optical and hypothalamic structures in order to prevent severe sequelae and therein minimize consequences that could negatively exacerbate patient quality of life. Because initial hypothalamic tumor involvement typically has an a priori, life-long effect on the clinical course (Müller, 2011) experienced by the patient, childhood, and adult onset craniopharyngioma should be recognized as chronic diseases requiring constant monitoring of the consequences and developing medical resources for treatment in order to provide not only optimal quality of life for patients, but also to garner additional information with the intent of minimizing what at present are severe consequences of both the disease and its treatment.

\section{REFERENCES}

Bartels, U., Laperriere, N., Bouffet, E., and Drake, J. (2012). Intracystic therapies for cystic craniopharyngioma in childhood. Front. Endocrinol. (Lausanne) 3:39. doi: 10.3389/fendo.2012.00039

Bingham, N. C., Rose, S. R., and Inge, T. H. (2012). Bariatric surgery in hypothalamic obesity. Front. Endocrinol. (Lausanne) 3:23. doi: 10.3389/fendo.2012.00023

Cohen, M., Guger, S., and Hamilton, J. (2011). Long term sequelae of pediatric craniopharyngioma - literature review and 20 years of experience. Front. Endocrinol. (Lausanne) 2:81. doi: 10.3389/fendo.2011.00081

Elfers, C. T., and Roth, C. L. (2011). Effects of methylphenidate on weight gain and food intake in hypothalamic obesity. Front. Endocrinol. (Lausanne) 2:78. doi: 10.3389/ fendo.2011.00078

Flitsch, J., Müller, H. L., and Burkhardt, T. (2011). Surgical strategies in childhood craniopharyngioma. Front. Endocrinol. (Lausanne) 2:96. doi: 10.3389/fendo.2011.00096

Kortmann, R.-D. (2011). Different approaches in radiation therapy of craniopharyngioma. Front. Endocrinol. (Lausanne) 2:100. doi: 10.3389/fendo.2011.00100

Lustig, R.H. (2011). Hypothalamic obesity after craniopharyngioma: mechanisms, diagnosis, and treatment. Front. Endocrinol. (Lausanne) 2:60. doi: 10.3389/fendo.2011.00060

Müller, H. L. (2011). Diagnostics, treatment, and follow-up in craniopharyngioma. Front. Endocrinol. (Lausanne) 2:70. doi: 10.3389/fendo.2011.00096

Puget, S. (2012). Treatment strategies in childhood craniopharyngioma. Front. Endocrinol. (Lausanne) 3:64. doi: 10.3389/fendo.2012.00064

Roth, C.L. (2011). Hypothalamic obesity in patients with craniopharyngioma: profound changes of several weight regulatory circuits. Front. Endocrinol. (Lausanne) 2:49. doi: 10.3389/fendo.2011.00049

Trippel, M., and Nikkhah, G. (2012). Stereotactic neurosurgical treatment options for craniopharyngioma. Front. Endocrinol. (Lausanne) 3:63. doi: 10.3389/ fendo.2012.00063

Zoicas, F., and Schöfl, C. (2012). Craniopharyngioma in adults. Front. Endocrinol. (Lausanne) 3:46. doi: 10.3389/fendo.2012.00046

Received: 21 May 2012; accepted: 31 May 2012; published online: 04 July 2012. Citation: Müller HL (2012) Craniopharyngioma - a childhood and adult disease with challenging characteristics. Front. Endocrin. 3:80. doi: 10.3389/fendo.2012.00080 This article was submitted to Frontiers in Pituitary Endocrinology, a specialty of Frontiers in Endocrinology.

Copyright () 2012 Müller. This is an open-access article distributed under the terms of the Creative Commons Attribution License, which permits use, distribution and reproduction in other forums, provided the original authors and source are credited and subject to any copyright notices concerning any third-party graphics etc. 